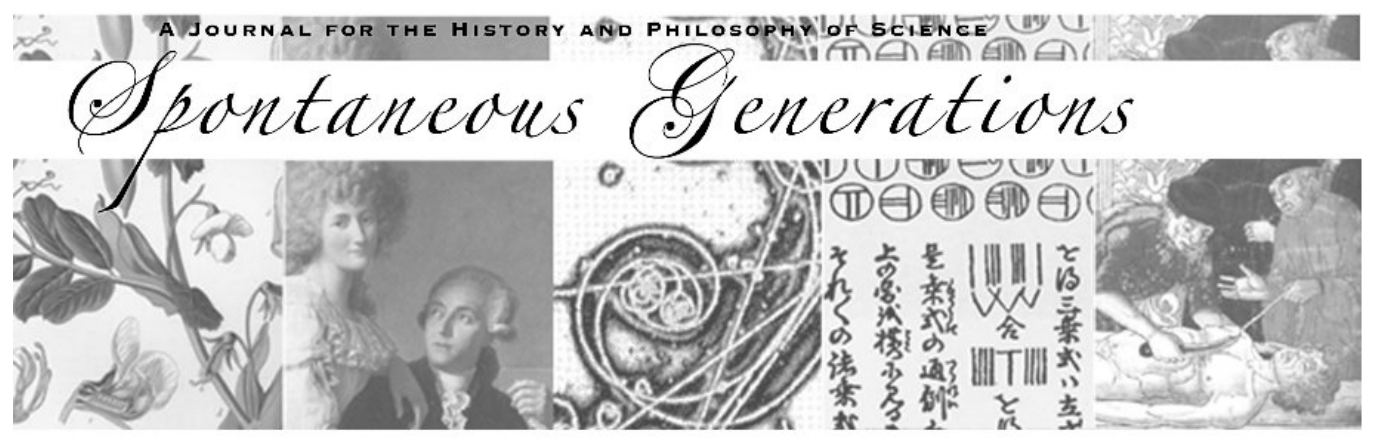

The Challenge of Authenticating Scientific Objects in Museum Collections: Exposing the Forgery of a Moroccan Astrolabe Allegedly Dated 1845 CE

Author(s): Ingrid Hehmeyer

Source: Spontaneous Generations: A Journal for the History and Philosophy of Science, Vol. 4, No. 1 (2010) 8-20.

Published by: The University of Toronto

DOI: $10.4245 /$ sponge.v4i1.13025

EDITORIAL OFFICES

Institute for the History and Philosophy of Science and Technology

Room 316 Victoria College, 91 Charles Street West

Toronto, Ontario, Canada M5S $1 \mathrm{~K} 7$

hapsat.society@utoronto.ca

Published online at jps.library.utoronto.ca/index.php/SpontaneousGenerations ISSN 19130465

Founded in 2006, Spontaneous Generations is an online academic journal published by graduate students at the Institute for the History and Philosophy of Science and Technology, University of Toronto. There is no subscription or membership fee. Spontaneous Generations provides immediate open access to its content on the principle that making research freely available to the public supports a greater global exchange of knowledge. 


\title{
The Challenge of Authenticating Scientific Objects in Museum Collections Exposing the Forgery of a Moroccan Astrolabe Allegedly Dated $1845 \mathrm{CE}^{*}$
}

\author{
Ingrid Hehmeyer
}

\begin{abstract}
The astrolabe is an instrument designed to measure the altitude of celestial bodies in order to tell time by day or by night. An astrolabe in the Royal Ontario Museum's collections was acquired at auction in 1988. According to the auction catalogue, it was made in Morocco, dated 1845. Years later, in preparation for a university course on the history of science, this writer's scrutiny of the astrolabe's inscribed features and physical condition suggested that it was a forgery. The paper explains the reasoning behind the judgement of falsehood.
\end{abstract}

Identification of a prominent museum object as a forgery is usually widely publicized and presented as a scandal. Inevitably, questions are asked such as "how can it possibly be that the museum bought this piece, that no curator until now discovered its deficiencies, or at least raised serious concerns?" The blame is to be put on the museum and its experts, their lack of competence or-at any rate-careless dealings. It is, therefore,

* Received 13 May 2010.

$\dagger$ Dr. Ingrid Hehmeyer, Associate Professor in the History of Science and Technology, Ryerson University, Toronto, is an agricultural engineer who specializes in human-environmental relationships in the arid regions of ancient and mediaeval Arabia. Her current field research focusses on the history of water technology in mediaeval Yemen, where she investigates technical innovations in hydraulic engineering and strategies for water management that allowed people to live under harsh environmental conditions. Part of this project involves a study of the methods of astronomical timekeeping used for allocating water, during both day and night. Her second area of research is the history of the medical sciences in the Islamic world. As a licensed pharmacist, she is particularly interested in the use of medicinal substances and their manufacture, and she has studied the pharmaceutical utensils from the mediaeval Islamic period housed at the Royal Ontario Museum, Toronto. The perpetual menace of disease on the one hand, and of water scarcity on the other-the two most fundamental threats to the basis of life-led people to resort to magical measures in the hopes that these might change the course of events. Tangible evidence for this exists in the form of magic-medicinal bowls, talismans and astrological symbols, which form a major theme in her research.

Spontaneous Generations 4:1 (2010) ISSN 1913-0465. University of Toronto. 
not surprising that museums tend to keep quiet about questionable artifacts, not only to protect their curators but, more importantly, because "the reputation of objects in museum collections is as sensitive as that of Caesar's wife" (Pope 1968, A/7). Museum visitors and readers of a catalogue are normally under the impression that a certain collection contains nothing but top-quality pieces, while it is a reality that most museums have fakes in their collections and are very much aware of it. Presenting the subject of forgeries-both ancient and modern-openly to the public in an exhibition is still the exception. ${ }^{1}$

In a 1968 publication "On the Discovery of Falsification and the Recognition of Authenticity," Arthur Pope (1968, A/1) pointed out that while acceptance of a forgery clearly puts the expert in an awkward position, erroneous rejection of a genuine object as false is likely to have more serious consequences. It will bring down the artifact's value, both monetarily and-more importantly-in a non-material way, that is, with regard to a piece's ideal value as part of the collection as a whole. Curators and dealers alike will be reluctant to take any further risks with the object. It is likely to end up in the bottom drawer of a storage cabinet or may even be de-accessioned. Thus, if an authentic piece is condemned mistakenly, its potential contribution to our understanding of cultural history will be lost. A so-far-unidentified fraud on the other hand forms part of a collection that is open to the public and under close and continuous scrutiny by scholars. This will eventually lead to the detection of its deficiencies. Acceptance of a forgery is therefore likely to be temporary, while erroneous rejection of a genuine artifact tends to have a much longer-lasting effect. Clearly, the curator's responsibility in verifying an object requires skill, care and diligence. It may involve a variety of approaches.

Art historical examination of museum pieces is based on "knowledge of period styles, their developments, variations, regional peculiarities, adaptations to variant media, and [...] the background iconography of different periods" (Pope 1968, A/1). Artifacts that do not fit into the well-studied and firmly established context of comparanda pose a problem. Out of precaution curators may be tempted to reject objects that are unusual because they are without precedent. This is particularly unfortunate in a case where a unique piece may actually be genuine.

Today's curators also have a range of analytical techniques at their disposal. Museum artifacts are regularly investigated in laboratories according to the latest scientific methods such as the application of

1 As an example, the Royal Ontario Museum in Toronto showed from January to April 2010 an exhibition entitled "Fakes and Forgeries: Yesterday and Today." 
chemistry and physics to materials analysis. ${ }^{2}$ Depending on the questions asked, a scholar studying an object should take both an art historical and an analytical approach into consideration, in particular when the matter of authenticity is at stake.

Curators of collections of scientific instruments can pursue a third line of enquiry to examine an artifact. Since the objects themselves reflect scientific principles and the state of scientific knowledge at the time of their manufacture, scrutiny of the detailed scientific data may reveal inconsistencies, discrepancies or outright mistakes. While the possibility exists that an instrument has been made in all honesty as a replica by a craftsman whose understanding of the scientific principles was less than perfect, this explanation can only account for certain problematic attributes. Copying a genuine, functioning instrument may result in minor mistakes; when the underlying scientific principles are distorted, however, the expert historian of science should become highly suspicious.

This phenomenon is well exemplified by the presentation here of a museum object that has to be judged a forgery. The object in question is an astrolabe. To appreciate the reasoning behind the judgement of falsehood, we must first present the history and basic operation of an astrolabe.

\section{HISTORY OF THE ASTROLABE}

One may surmise that observing the movement of the heavenly bodies has been an intimate part of peoples' lives since very early times. The attempt to understand the regularities of that motion led eventually to the development of devices for astronomical observation and measurement. One such instrument is a portable item called an astrolabe, designed to measure the altitude of the celestial bodies in order to determine a variety of astronomical (and also topographical) correlations. ${ }^{3}$ Amongst its practical applications, the astrolabe was used for telling time, both by night and by day. This was of great significance in early Muslim society because of the need to establish the hour of the five daily prayers. It is, therefore, not surprising that the astrolabe became the most widely used astronomical instrument during classical Islamic times and was employed in the Middle East as well as in Europe until the eighteenth century for telling time and, more generally, for observational astronomy. Throughout its long period of use, the astrolabe did not undergo more than very minor changes and remained basically unaltered, confirming that the underlying astronomical principles were fully developed and allowed the instrument to perform its

2 Practical examples are given, for instance, in Goldstein et al. (2003).

${ }^{3}$ Among the three different groups of astrolabes, the most common one is the planispheric or flat astrolabe, which forms the focus of this paper. 
operations with precision (Hartner 1939, 2530, 2534).

While the term "astrolabe" itself is derived from the Greek astrolabos, no specimens from ancient Greek times seem to be preserved. ${ }^{4}$ The earliest known dated astrolabe is from the Islamic world and is housed today in the National Museum of Kuwait. It was made in Iraq in the year 927-28 (Atıl 1990, 84-85). Evidence predating this instrument does exist, though, in the written sources. ${ }^{5}$ Masha'allah, a Jewish astronomer and astrologer (d. c. 815) who worked in Baghdad during the early Abbasid caliphate, is credited with authorship of the oldest known Arabic treatise on the astrolabe. While his "Book on the Construction of an Astrolabe and Its Use" has not survived in the original Arabic, a Latin translation from 1276 is extant. ${ }^{6}$ The earliest Arabic description of the astrolabe that is preserved in the original, together with detailed instructions for its use, was composed in the ninth century by a certain 'Ali Ibn 'Isa, an experienced observational astronomer. $^{7}$

\section{BRIEF DESCRIPTION OF THE INDIVIDUAL PARTS OF THE INSTRUMENT AND ITS USE}

The following summary is based on three sources. Willy Hartner's 1939 elaboration is the most thorough one and provides the framework. Among the numerous descriptions that have appeared since then, John North's 1974 article gives a synopsis of the underlying scientific principles of the astrolabe. Francis Maddison's contribution (1997, 200-05) has a practical focus and illustrates very succinctly the different steps involved in taking a reading with the instrument. He employs a Moroccan astrolabe made at the beginning of the eighteenth century for his demonstration.

${ }^{4}$ See Neugebauer (1949) for an overview of the pre-Islamic history of the astrolabe.

${ }^{5}$ King (1981) gives a detailed overview of the origin and history of the instrument as derived from the mediaeval Islamic texts.

${ }^{6}$ See Gunther $(1929,137-231)$ for the English translation and the edited Latin text. The attribution of the work to Masha'allah has been questioned, though, by Paul Kunitzsch (1966, 47-58 and, in more detail, 1981, 42-56). This manuscript on the astrolabe that is associated with Masha'allah was "the most popular and widespread treatise on the subject in the middle ages" (Kunitzsch 1981, 42) and acquired fame because the fourteenth-century astronomer-poet Geoffrey Chaucer used it as the basis for his own work on the astrolabe which was the first one written on the subject in English. For background information on Masha'allah see Pingree (1974).

7 The text was translated into German by Schoy (1927). Much of it reads like a practical handbook on how to operate the instrument. 


\section{Astrolabe assembly}

The astrolabe (Figures 1 and 2), a portable circular instrument with a diameter of some ten to twenty $\mathrm{cm}$, must be hung during use and therefore has a suspension device attached to the body. The latter is called the "mother" and consists of a front and a back. The raised outer rim of the front encloses a number of thin disks that are fitted one above the other into the recess of the mother. The disks and the mother have a hole bored through their centre and the parts are held together by a pin that passes through this hole. A wedge, usually in the shape of a horse's head and therefore called the "horse", is inserted in the slot of the pin to keep it in place. The pin also serves as the axis for the two movable parts of the astrolabe: these are the "spider" (or rete) on the front, and the alidade (a flat ruler) on the back.

\section{Disks}

Both sides of the disks are engraved with a series of lines and circles representing a stereographic projection of the heavens for a specific geographical latitude. Stereography is the depiction of three-dimensional bodies in a plane. Each disk thus displays a flat map of coordinate lines that are fixed for an observer at one particular latitude, and the base line for the stereographic projection is the observer's horizon. In order to take a reading with the instrument, the disk for the correct latitude must be placed on top. The area below the horizon is divided into twelve sections by curved lines that indicate the unequal hours. ${ }^{8}$ The centre of each disk (and of the astrolabe as a whole, that is, the centre of the hole through which the pin passes) represents the north celestial pole.

\section{Spider}

The spider has the same diameter as the disks, but instead of being solid most of its surface is cut away, giving it a net-like appearance like that of a spider's web, hence the name. It is essentially a star map-a stereographic projection of the vault of the fixed stars. The positions of the most conspicuous ones in the night sky are indicated by pointers, which have the names of these stars engraved upon them. Rotation of the

8 In the Islamic world, a month begins with the first sighting of the crescent moon in the early evening sky, just after sunset. Therefore, the day begins at sunset. The night from sunset to sunrise is divided into twelve hours, and the same applies to the day from sunrise to sunset. Thus, the length of these hours varies during the year and from one geographical location to another (a night hour, as one twelfth of the period between sunset and sunrise, is longer during the winter than during the summer; in more northerly latitudes, a winter night hour is longer than one closer to the equator). 


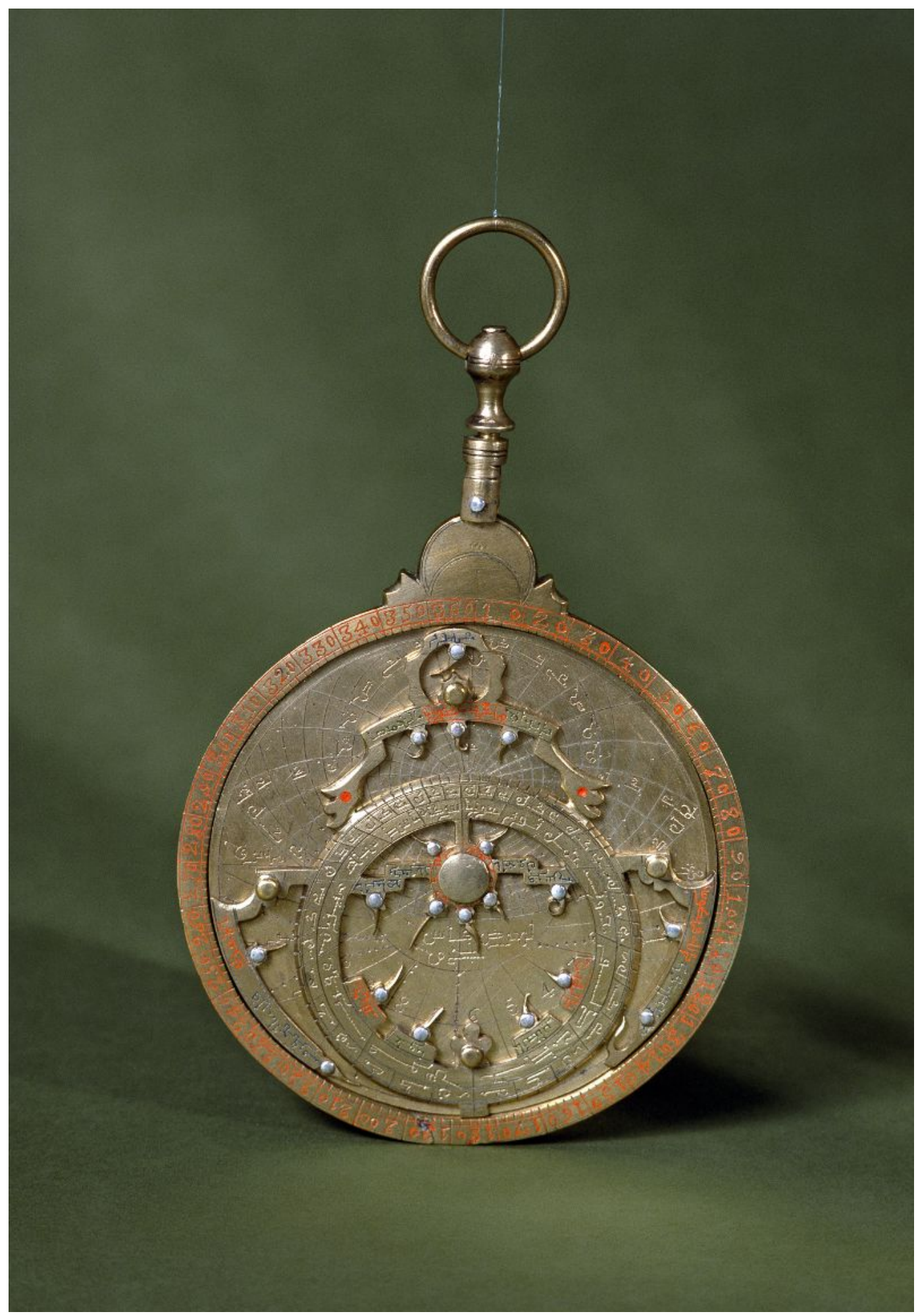

Figure 1. The ROM's astrolabe (988.118.1, front, with permission of the Royal Ontario Museum (C) ROM). 


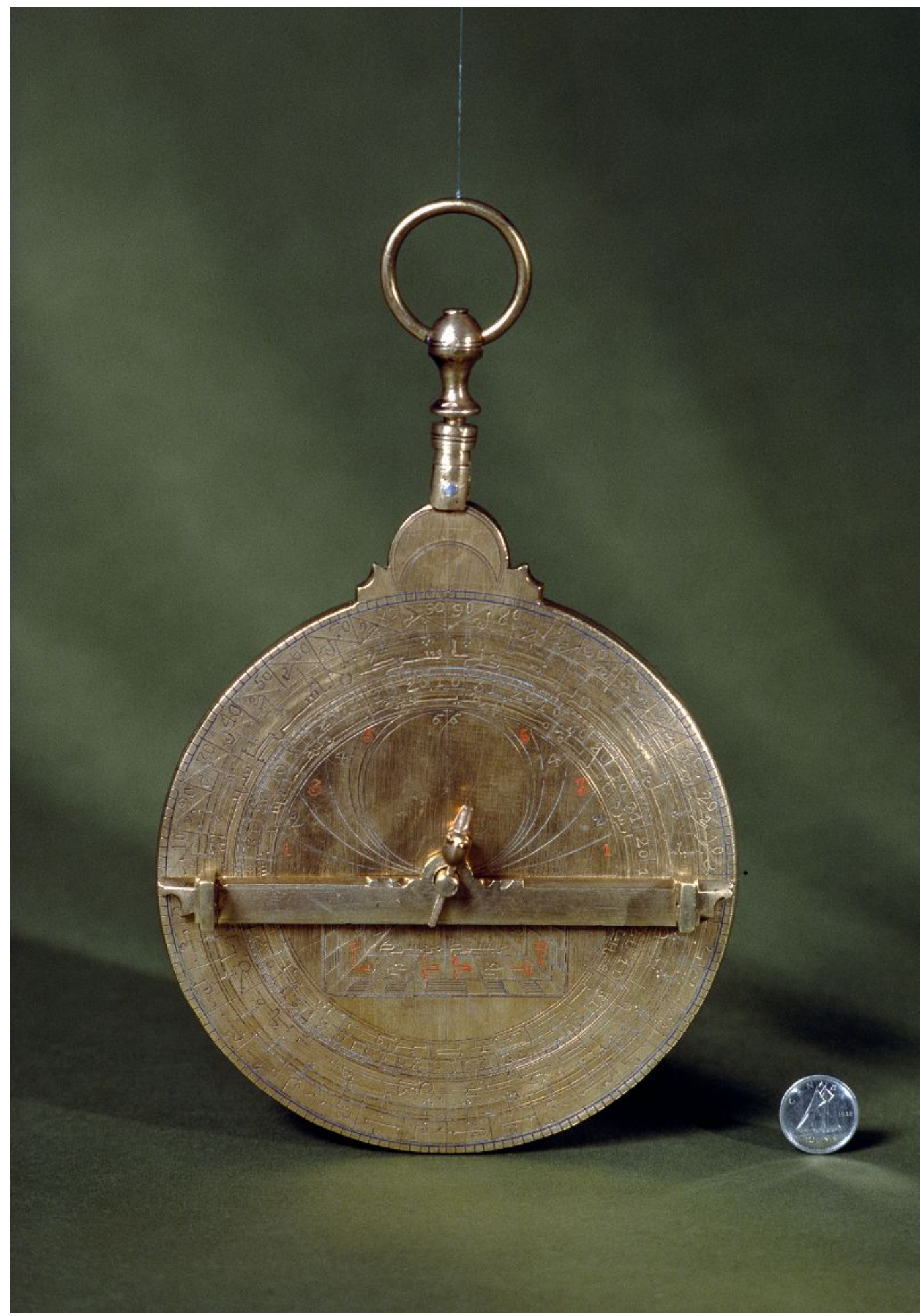

Figure 2. The ROM's astrolabe (back, with permission of the Royal Ontario Museum (C) ROM). 
spider around the pin demonstrates the revolution of the fixed stars around the earth at rest, as represented by the disk underneath the spider. If the spider was solid, the disk with its coordinate system would not be visible. The spider also carries an off-centre circle. This is the circle of the zodiac which is divided into twelve parts, corresponding to the twelve signs. Their names are written around the rim.

\section{Front and back of mother}

The raised outer rim of the front is graduated from zero to 360 degrees, starting in the middle of the suspension device. While the design of the front of the instrument with its disks and the spider always follows the described arrangement, the back of the mother can carry a range of designs. Usually, the centre of the back is divided into four quadrants that are engraved with mathematical functions, including the trigonometrical functions. As on the front, the outer band is graduated into degrees. In Figure 2 the degree scale is numbered at intervals of ten degrees, starting from the horizontal diameter. Moving inwards, the next band carries a zodiac scale, with each of the twelve zodiac signs occupying a segment of thirty degrees. The innermost band displays a solar calendar scale that is divided proportionately into the twelve months of the Julian calendar, and each month is subdivided into its respective number of days. The fact that the back carries a calendar scale, together with a zodiac scale, allows correlation of a specific date with the sun's position on the ecliptic for that day.

\section{Alidade}

The moveable alidade at the back of the mother, a flat ruler which turns around the pin, serves as the sighting device. It is equipped with two rectangular plates that are affixed at right angles to the alidade, at both ends. Each of the vanes has a sighting hole bored through it.

\section{Operation of the astrolabe}

In preparation for taking a sighting with the instrument, the observer places beneath the spider the disk appropriate for his geographical latitude. Since the instrument must hang freely during use, the observer holds the instrument by the ring of the suspension device, see Figures 1 and 2. He chooses for the sighting a fixed star, one that is marked on the spider and that can be seen clearly in the sky. The alidade is turned until the star is sighted through both holes. Its altitude is then read on the degree scale. At the same time, the calendar date on which the 
observation is made can be correlated with the zodiac scale. This gives the sun's position on the ecliptic for the day of observation.

The astrolabe is turned over and the spider is rotated until the tip of the pointer for the star coincides, on the disk immediately beneath, with the appropriate coordinate line for celestial altitude (the number of degrees as read on the back). The instrument, both front and back, is thus set for the moment of observation.

The last step involves determining the time by extending a straight line (usually in the form of a thread or rule) from the centre of the astrolabe (representing the north celestial pole) through the position of the sun on the ecliptic (on the spider's circle of the zodiac). This line cuts one of the curved lines indicating the unequal hours on the disk beneath. If, for instance, the line for the third hour is cut, three hours have passed since sunset, and nine hours remain until sunrise.

\section{The Royal Ontario Museum's astrolabe}

The astrolabe from the Royal Ontario Museum's collections (inventory number 988.118.1, diameter thirteen cm, brass) was bought in 1988 at an auction house in Europe. The instrument is engraved with (imitation) Kufic script and some European-style Hindu-Arabic numerals. It has three disks:

1. for latitudes $31^{\circ} 30^{\prime}$ (Marrakesh) and $33^{\circ}$ (Salé),

2. for latitudes $33^{\circ} 40^{\prime}$ (Fez) and $34^{\circ}$ (Meknès),

3. for latitude $30^{\circ}$ (Sijilmasa), and a horizon tablet.

The spider carries pointers to nineteen named stars. According to the auction house's catalogue entry, its provenance is Morocco and it is dated AH 1261 (1845 CE). Some years ago, in preparation of a university class on the history of science in the Islamic world, this writer took the instrument apart in order to study the astronomical details. An inscription in the recess of the front of the mother includes a date, written in European-style numerals, which was, surprisingly, found not to coincide with the one in the catalogue. Instead, the instrument is dated AH 1126 (1714-15 CE) and therefore seems to be considerably older than assumed. Soon it was discovered that, on the calendar scale, the month of December has a record of thirty-two days, and that the date for the vernal equinox is wrong (March 6; the correct date for the year AH $1126=1714-15$ CE would be March 9). ${ }^{9}$ The ROM's archaeological metals conservator looked at the instrument under a microscope and confirmed that the engravings were

${ }^{9}$ Please note that the maker of the astrolabe followed the Julian calendar. 
made with an electrical tool and that the alleged red enamel is, in fact, plastic.

The astrolabe's home department at the ROM was divided: while some colleagues considered the instrument a useless modern forgery, others were more polite and suggested it was a replica-that is, an exact copy of a functioning astrolabe-in which case one might be able to find the original object in an exhibition or museum catalogue. A lengthy search was eventually successful when an image of a similar astrolabe was discovered in a catalogue of the collection of the Time Museum in Rockford, Illinois (inv. 430, see Turner $1985,108-11) .{ }^{10}$ Initially, this seemed to suggest that the ROM's piece was indeed a replica of the Time Museum's instrument. But careful comparison with the photograph in the catalogue showed that both objects shared all the same nicks and scratches. Was it, in fact, the very same astrolabe?

Interestingly, the Time Museum's catalogue entry discusses the date of the instrument as being problematic. The Arabic inscription in the recess of the mother gives the name of the maker as Muhammad b. al-Mufaddal $b$. Ahmad b. Kiran. This man, a professional mosque timekeeper (muwaqqit) from Wazzan in Morocco, is a known astrolabist. A second instrument made by him is housed in the Adler Planetarium in Chicago (A-77, see Pingree 2009, xv, 33-35). ${ }^{11}$ Two quadrants bearing Muhammad b. al-Mufaddal's name are in private collections in Paris and Fez. All three objects are dated to the same year, namely AH 1264 (1847-48 CE). Anthony Turner, the author of the Time Museum's catalogue, therefore, suggests that the engraver of the astrolabe in question was unfamiliar with European numerals and made a mistake by confusing their positions. Instead of the Muslim calendar date 1126 (1714-15 CE) presented on the instrument, he intended to write 1261 (1845 CE), which would be around the time when Muhammad $\mathrm{b}$. al-Mufaddal made his other pieces (Turner 1985, 108, n. 259). ${ }^{12}$ In a footnote (111, n. 261), Turner also mentions the close resemblance of traits of manufacture and style to those of an (unsigned) astrolabe in the Museum of the History of Science in Oxford (no. 155, see Gunther 1932, i, 300-01, and Plate LXVIII). ${ }^{13}$ The

${ }^{10}$ The Time Museum was founded in 1971. Following its closure in 1999, the collection was sold.

${ }^{11}$ Comparison with the ROM's astrolabe shows a close similarity between the types of script that are used for the engravings.

${ }^{12}$ The author states that the date of March 6 for the vernal equinox, as given on the astrolabe, seems to confirm his assumption, since in the Julian calendar that Muhammad b. al-Mufaddal followed it is the correct date for the mid-nineteenth century (Turner 1985, 108, n. 259). This is, in fact, not the case: the date should be March 8.

${ }^{13}$ Gunther's catalogue entry dates this piece to c. $1780 \mathrm{CE}$. 
latter instrument has a horizontal, inverted crescent moon engraved on the suspension device, a unique style characteristic. Suspiciously, it is repeated on the astrolabe that provides the core substance of this article (see Figures 1 and 2). Clearly, the author of the Time Museum's catalogue examined the instrument carefully. However, he does not suggest the possibility that the object might be problematic.

The unavoidable fact is that someone in the age of plastic and electrical tools made an astrolabe that cannot function properly, while copying names, decorations and some astronomical details from genuine instruments. When the Time Museum decided to de-accession the piece, its earlier published catalogue entry provided credible authentication and enhanced its potential auction value. The Time Museum's catalogue was published in 1985, and the ROM bought the object in 1988.

\section{CONCLUSION}

Astrolabes are not only useful astronomical instruments, but also prized collectors' items. The design of the spider in particular ranges from geometric to floral and reflects the artistic imagination of the maker. Astrolabes are usually the pride of a museum's collection and sought-after objects at international auctions. It is, therefore, not surprising that forgeries are an ever-present problem on the antique market. ${ }^{14}$ Forgeries exist in museum and private collections alike. ${ }^{15}$ It takes courage, though, to publish a forgery in a catalogue.

Part of the Nasser D. Khalili Collection of Islamic Art in London (GB) is a very fine collection of scientific instruments. When the catalogue of this collection was published in 1997, the chapter on astrolabes included a brief section on fakes and forgeries (Maddison 1997, 195-96, 254-55), scientifically inaccurate or even astronomically useless and unusable, yet aesthetically appealing pieces. The 2009 catalogue of the Adler Planetarium \& Astronomy Museum in Chicago also contains twelve fake astrolabes (Pingree 2009, 172-95). For someone studying scientific instruments, forgeries can be of particular interest. While identifying the mistakes a forger made demands thorough understanding of the underlying scientific principles involved, the cover-ups by the dealers add another intriguing nuance. Successful scrutiny of a fake is challenging detective work.

${ }^{14}$ Gingerich (1982) gives a brief overview of the most typical characteristics that identify an astrolabe as a fake.

${ }^{15}$ The dealings of the many players involved in the "forgery culture" have been spelled out in detail by Oscar Muscarella (2000, 1-29). 
Forgery of astrolabes is often considered a modern phenomenon, ${ }^{16}$ but the tradition seems to go back to the eighteenth century. The reason for making these early fakes was the same as today and is neatly summed up in a mid-nineteenth century report by a foreign resident in Iran. He describes that at that time some astrolabes bearing the names of renowned makers could still be found in Tehran. The high quality instruments made by a certain 'Abd al-A'imma, a prominent, very prolific and talented astrolabist of the late seventeenth and early eighteenth century, ${ }^{17}$ were especially sought-after curiosities of the wealthy and the influential at court. These people were prepared to pay vast sums of money for such an object, "even though some of them did not understand one iota of it" (Krziž 1904-05, 121-22).

\section{ACKNOWLEDGEMENTS}

I am grateful to Susan Stock, Archaeological Metals Conservator, Royal Ontario Museum, Toronto, for scrutiny of the astrolabe under her microscope. The images of the astrolabe 988.118.1 are presented with permission of the Royal Ontario Museum (C) ROM.

INGRID HEHMEYER

Department of History

Ryerson University

350 Victoria Street

Toronto, ON M5B 2K3

Canada

ihehmeye@ryerson.ca

\section{REFERENCES}

Atıl, Esin, ed. 1990. Islamic Art \& Patronage. Treasures from Kuwait. New York: Rizzoli.

Gingerich, Owen. 1982. Fake astrolabes. Sky and Telescope 63: 465-68.

Gingerich, Owen, David King, and George Saliba. 1972. The 'Abd al-A'imma Astrolabe Forgeries. Journal for the History of Astronomy 3: 188-98.

Goldstein, Joseph I., Dale E. Newbury, Patrick Echlin, David C. Joy, Charles E. Lyman, Eric Lifshin, Linda Sawyer, and Joseph R. Michael. 2003. Scanning Electron Microscopy and X-Ray Microanalysis, 3rd ed. New York: Kluwer Academic and Plenum Publishers.

${ }^{16}$ Nasr (1976, 121, Plate 79) shows a photograph of what the author describes rather diplomatically as a "contemporary master astrolabe maker of Isfahan."

${ }^{17}$ See Gingerich, King and Saliba (1972) for details on 'Abd al-A'imma. 
Gunther, Robert T. 1929. Chaucer and Messahalla on the Astrolabe (Early Science in Oxford V). Oxford: University Press.

Gunther, Robert T. 1932. The Astrolabes of the World. 2 vols. Oxford: University Press.

Hartner, Willy. 1939. The principle and use of the astrolabe. In A Survey of Persian Art from Prehistoric Times to the Present, ed. Arthur U. Pope, vol. III, 2530-54 (Plates 1397-1402). London: Oxford University Press.

King, David A. 1981. The Origin of the Astrolabe According to the Medieval Islamic Sources. Journal for the History of Arabic Science 5: 43-83.

Krziž, A. 1904-05. Das persisch-arabische Astrolabium des Ab-dul Aiméh. Das Weltall 5: 121-30, 144-52.

Kunitzsch, Paul. 1966. Typen von Sternverzeichnissen in astronomischen Handschriften des zehnten bis vierzehnten Jahrhunderts. Wiesbaden: Harrassowitz.

Kunitzsch, Paul. 1981. On the Authenticity of the Treatise on the Composition and Use of the Astrolabe Ascribed to Messahalla. Archives Internationales d'Histoire des Sciences 31, no. 106 (Juin): 42-62.

Maddison, Francis. 1997. The planispheric astrolabe. In Science, Tools \& Magic (The Nasser D. Khalili Collection of Islamic Art XII), ed. Francis Maddison and Emilie Savage-Smith, vol. I, 186-211. London und Oxford: The Nour Foundation in association with Azimuth Editions and Oxford University Press.

Muscarella, Oscar W. 2000. The Lie Became Great: The Forgery of Ancient Near Eastern Cultures (Studies in the Art and Archaeology of Antiquity I). Groningen: Styx.

Nasr, Seyyed Hossein. 1976. Islamic Science. An Illustrated Study. [London:] World of Islam Festival Publishing Company.

Neugebauer, Otto. 1949. The Early History of the Astrolabe (Studies in Ancient Astronomy IX). Isis 40, no. 3 (August): 240-56.

North, John D. 1974. The Astrolabe. Scientific American 230, no. 1 (January): 96-106.

Pingree, David. 1974. Māshā'allāh. In Dictionary of Scientific Biography IX: 159-62. New York: Charles Scribner's Sons.

Pingree, David. 2009. Eastern Astrolabes (Historic Scientific Instruments of the Adler Planetarium \& Astronomy Museum II). Chicago, IL: Adler Planetarium \& Astronomy Museum.

Pope, Arthur U. 1968. On the Discovery of Falsification and the Recognition of Authenticity. In A Survey of Persian Art from Prehistoric Times to the Present, ed. Arthur U. Pope, vol. XIII, A/1-A/10. Tehran: Persian Art.

Schoy, Carl. 1927. 'Alī ibn 'Īsā, Das Astrolab und sein Gebrauch. Isis 9, no. 2 (June): 239-54.

Turner, Anthony J. 1985. The Time Museum: Catalogue of the Collection. Vol. 1: Time Measuring Instruments; Part 1: Astrolabes, Astrolabe Related Instruments. Rockford, IL: The Time Museum. 